\title{
Estimation of strain accumulation of densification network in Northern Marmara Region, Turkey
}

\author{
I. Deniz ${ }^{1}$ and H. Ozener ${ }^{2}$ \\ ${ }^{1}$ Istanbul Technical University, Department of Geomatics Engineering, Istanbul, Turkey \\ ${ }^{2}$ Bogazici University, Kandilli Observatory and Earthquake Research Institute, Department of Geodesy, Istanbul, Turkey
}

Received: 25 June 2010 - Revised: 3 August 2010 - Accepted: 3 September 2010 - Published: 8 October 2010

\begin{abstract}
Strain analysis is one of the methods for the kinematic analysis of the repeated geodetic measurements. In order to derive strain accumulation in Marmara Region, different institutions carried out several Global Positioning System (GPS) campaigns in 1999 and 2006. The GPS campaigns were performed on the geodetic network which cover the provinces: Kirklareli, Tekirdag, Bursa, Bilecik and Adapazari. Then, the displacements of the network stations were estimated by means of analysing the GPS space geodetic measurements. For the assessment of the datum differences between 1999 and 2006 on the station coordinates, 3-D Helmert transformation was applied to the coordinates of each 1999 and 2006 datum. Then, a global test was introduced to determine the significant deformation which occurred in the geodetic GPS network. Strain accumulation with a finite element model was then computed. First, triangles were constructed for the whole network with the Delaunay method. Hereafter, strain parameters were calculated for each triangle. Maximum values of strain accumulation were found around the surroundings of Marmara Ereglisi and Izmit, whereas minimum values are around Istanbul.
\end{abstract}

\section{Introduction}

After the Izmit and Duzce earthquakes (1999), renovations of Turkish National Fundamental GPS Network (TNFGN) and Turkish National Vertical Control Network (TNVCN) were done (TNFGN Report, 2001). Their station coordinates at the 2000.45 epoch were estimated. Densification networks tied to TNFGN and TNVCN were established by the institutions, i.e. Geodesy Department of Kandilli Observatory and Earthquake Research Institute of Bogazici University,

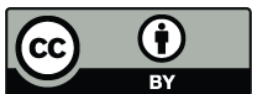

Correspondence to: $\mathrm{H}$. Ozener

(ozener@boun.edu.tr)
Istanbul Metropolitan Municipality, General Command of Mapping (GCM), General Directorate of Land Registry and Cadastre, and the Scientific and Technical Research Council of Turkey (TUBITAK) - Marmara Research Center (MRC) in Kirklareli, Tekirdag, Bursa, Bilecik and Adapazari. Istanbul GPS Triangulation Network (IGTN) and Marmara Earthquake Region Land Information System (MERLIS) were formed covering this region (IGTN Report, 1999; MERLIS Report, 2006). To conclude, GPS campaigns were performed and analysed at different times by different institutions.

A test network was formed from a subset of the network stations of Turkish Continuously Operating Reference Stations (CORS-TR). Several GPS campaigns were performed on this network and analysed between 15 July and 30 October 2006 by three different companies namely TOPCON, TRIMBLE, and LEICA in order to test the performance of the GPS receivers (CORS-TR, 2006). Each company performed the measurements and evaluations using their own equipments.

This study aimed to compare the coordinate differences between the adjusted coordinates obtained from GPS observations in 1999 (converted to 2000.45 epochs) and the average of the adjusted coordinates obtained from the GPS observations by the aforementioned three companies in 2006 (converted to 2006.60 epochs) and to compute strain accumulation of the corresponding area by finite element model.

\section{Test network and observations}

Test network of CORS-TR was composed of 115 geodetic stations settled in Marmara Region which were chosen from the geodetic networks: TNFGN, MERLIS and IGTN. The datum of the so-called test network of CORS-TR was assigned by fixing the station coordinates of TNFGN to their a priori values at epoch 2000.45. Moreover, TNFGN network datum was constrained on International GNSS Service (IGS)

Published by Copernicus Publications on behalf of the European Geosciences Union. 


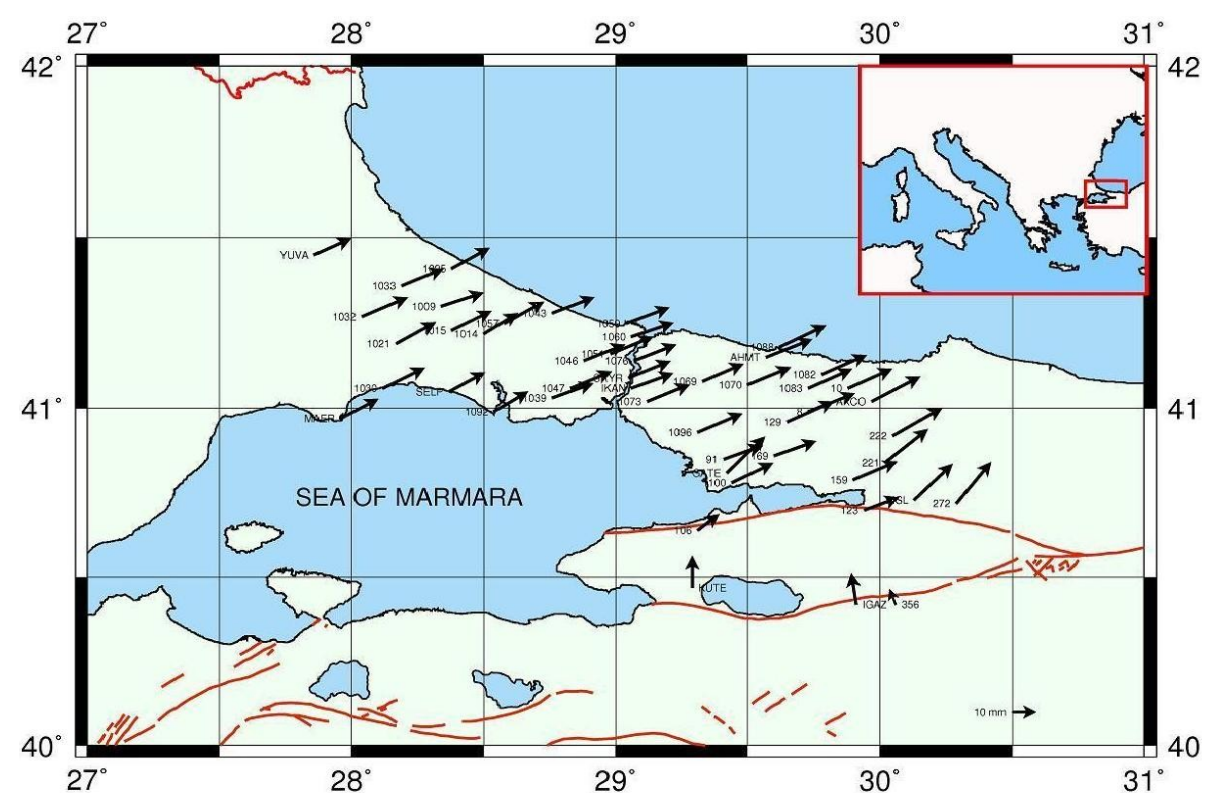

Fig. 1. The study area and the displacement vectors between ITRF96 solution at epoch 2000.45 and ITRF2000 solution at epoch 2006.60 on the test network of CORS-TR.

network ITRF96 coordinates of the IGS stations: ONSA, MADR, WTZR, MATE, ANKR, ZWEN, KIT3, NICO and BAHR. Another solution of the test network of CORS-TR GPS campaigns was carried out by fixing the IGS network defined in ITRF2000 at epoch 2006.60. In this case, test network of CORS-TR was fixed (a priori station coordinates were tightly constrained) to IGS network. The IGS stations, where coordinates are fixed to their a priori coordinates defined in ITRF2000 at epoch 2006.60, are namely ANKR, TUBI, DRAG, NOT1, SOFI, BUCU and MATE. Coordinates of the test network of CORS-TR stations estimated by two solutions have both different epochs and different datum. It is worth mentioning at this point that twelve ITRF realizations (solutions) have been successfully performed up to the present by International Earth Rotation and Reference Systems Service (IERS) including ITRF2008 which is the last release (Altamimi et al., 2007). The differences of transformation parameters of IERS, ITRF solutions are significant but too small in levels of magnitude, i.e. origin differences are in sub-centimetre level, rotation differences are in sub milli-arc-second level (mas) and scale differences are in part-per-billion level. The displacement vectors of the test network CORS-TR were calculated from the differences between the coordinates of ITRF96 datum (TNFGN datum) at epoch 2000.45 and ITRF2000 datum at epoch 2006.60. The displacement vectors between ITRF96 at epoch 2000.45 and ITRF2000 at epoch 2006.60 were shown in Fig. 1 and Table 1 .

\section{Investigation of datum}

To examine the effect of two datums with different epochs on the displacement vectors, 3-D Helmert transformation parameters were estimated between the coordinates of ITRF96 at epoch 2000.45 and in ITRF2000 at epoch 2006.60. IGS stations of TNFGN were in ITRF96 datum (Table 2), whereas IGS stations of CORS-TR were in ITRF2000 datum (Table 3). To analyse the datum of two epochs, the 3-D Helmert transformation was applied to coordinates of ITRF96 and ITRF2000 of IGS stations which made up the datum of two epochs. The results of the Helmert transformation are the datum parameters between the two terrestrial reference frame (TRF) solutions of the test network of CORS-TR. Thus, computed transformation parameters (three translations, three rotations and a scale factor) between ITRF96 at epoch 2000.45 and ITRF2000 at epoch 2006.60 were compared with each other. Transformation parameters of each epoch were given in Table 4.

Transformation parameters of TNFGN datum (Table 4) indicates that the coordinates of ITRF96 at epoch 1997 of IGS stations which made up datum of TNFGN were consistent with the coordinates of ITRF2000 at epoch 1997. However, there was a significant translation between ITRF96 at epoch 1997 and ITRF2000 at epoch 1997 of IGS stations which made up datum of CORS-TR. It could be said that translations had an influence on the displacement vectors.

Two epochs had different number and distribution of datum points, so there were significant datum parameters between datum of TNFGN and CORS-TR. These differences occurred as a component of the deformation vector. 
Table 1. Coordinates of stations and displacement vectors.

\begin{tabular}{|c|c|c|c|c|c|c|}
\hline \multirow[t]{2}{*}{$\begin{array}{l}\text { Station } \\
\text { ID }\end{array}$} & \multicolumn{2}{|c|}{$\begin{array}{c}\text { ITRF96, } \\
\text { at epoch } 2000.45 \text { coordinates }\end{array}$} & \multicolumn{2}{|c|}{$\begin{array}{c}\text { ITRF2000, } \\
\text { at epoch } 2006.60 \text { coordinates }\end{array}$} & \multicolumn{2}{|c|}{$\begin{array}{l}\text { Local topocentric horizontal } \\
\text { displacement }(\mathrm{m})\end{array}$} \\
\hline & $\begin{array}{l}\text { UTM North } \\
\text { (m) }\end{array}$ & $\begin{array}{l}\text { UTM East } \\
\quad(\mathrm{m})\end{array}$ & $\begin{array}{l}\text { UTM North } \\
\text { (m) }\end{array}$ & $\begin{array}{l}\text { UTM East } \\
\quad(\mathrm{m})\end{array}$ & $\begin{array}{l}\text { North } \\
\text { (m) }\end{array}$ & $\begin{array}{c}\text { East } \\
(\mathrm{m})\end{array}$ \\
\hline AHMT & 4558629.9657 & 716009.0616 & 4558630.0420 & 716009.2520 & 0.0763 & 0.1904 \\
\hline $\mathrm{AKCO}$ & 4544921.0451 & 749831.6047 & 4544921.1511 & 749831.8056 & 0.1060 & 0.2009 \\
\hline GATE & 4519935.3364 & 704228.1811 & 4519935.4903 & 704228.3381 & 0.1539 & 0.1570 \\
\hline IGAZ & 4478642.2053 & 746550.2237 & 4478642.3342 & 746550.2037 & 0.1289 & -0.0200 \\
\hline IKAN & 4547867.4598 & 673391.4453 & 4547867.5220 & 673391.6180 & 0.0622 & 0.1727 \\
\hline KUTE & 4482280.0875 & 693840.6258 & 4482280.2205 & 693840.6258 & 0.1330 & 0.0000 \\
\hline MAER & 4535938.7897 & 580774.3147 & 4535938.8730 & 580774.4700 & 0.0833 & 0.1553 \\
\hline SELP & 4545408.7113 & 614737.9823 & 4545408.7920 & 614738.1300 & 0.0807 & 0.1477 \\
\hline SISL & 4513406.5434 & 764510.8057 & 4513406.6955 & 764510.9646 & 0.1521 & 0.1589 \\
\hline SRYR & 4551063.7725 & 672248.2343 & 4551063.8430 & 672248.4070 & 0.0705 & 0.1727 \\
\hline YUVA & 4589200.4569 & 571920.0501 & 4589200.5260 & 571920.2030 & 0.0691 & 0.1529 \\
\hline 8 & 4542643.6284 & 729363.2981 & 4542643.7064 & 729363.4911 & 0.0780 & 0.1930 \\
\hline 10 & 4551702.5224 & 741939.1269 & 4551702.6034 & 741939.3078 & 0.0810 & 0.1809 \\
\hline 91 & 4526681.2330 & 703213.6371 & 4526681.2899 & 703213.7960 & 0.0569 & 0.1589 \\
\hline 106 & 4502862.6652 & 695700.1477 & 4502862.7322 & 695700.2346 & 0.0670 & 0.0869 \\
\hline 123 & 4511374.8130 & 748300.9752 & 4511374.8670 & 748301.1181 & 0.0540 & 0.1429 \\
\hline 129 & 4539113.5760 & 723497.5294 & 4539113.6620 & 723497.7203 & 0.0860 & 0.1909 \\
\hline 159 & 4521174.5075 & 745140.2310 & 4521174.5845 & 745140.4119 & 0.0770 & 0.1809 \\
\hline 169 & 4527929.1286 & 719270.4019 & 4527929.1906 & 719270.5758 & 0.0620 & 0.1739 \\
\hline 221 & 4525838.1926 & 754937.8958 & 4525838.3351 & 754938.0743 & 0.1425 & 0.1785 \\
\hline 222 & 4534247.0760 & 756584.6923 & 4534247.1932 & 756584.8957 & 0.1172 & 0.2034 \\
\hline 272 & 4513335.9567 & 778244.4418 & 4513336.1309 & 778244.5852 & 0.1742 & 0.1434 \\
\hline 356 & 4478839.4843 & 759791.7704 & 4478839.5449 & 759791.7472 & 0.0606 & -0.0232 \\
\hline 1009 & 4573042.9155 & 611960.8810 & 4573042.9730 & 611961.0570 & 0.0575 & 0.1760 \\
\hline 1014 & 4564348.4665 & 625422.7841 & 4564348.5530 & 625422.9240 & 0.0865 & 0.1399 \\
\hline 1015 & 4564919.1198 & 615900.1765 & 4564919.2020 & 615900.3420 & 0.0822 & 0.1655 \\
\hline 1021 & 4560644.1557 & 598502.3869 & 4560644.2460 & 598502.5500 & 0.0903 & 0.1631 \\
\hline 1025 & 4585338.9555 & 615468.9838 & 4585339.0430 & 615469.1410 & 0.0875 & 0.1572 \\
\hline 1030 & 4546449.0771 & 594320.3187 & 4546449.1630 & 594320.4920 & 0.0859 & 0.1733 \\
\hline 1032 & 4568711.7575 & 586879.3524 & 4568711.8390 & 586879.5420 & 0.0815 & 0.1896 \\
\hline 1033 & 4579699.9469 & 599700.7572 & 4579700.0180 & 599700.9300 & 0.0711 & 0.1728 \\
\hline 1039 & 4543623.0522 & 647782.5407 & 4543623.1140 & 647782.7090 & 0.0618 & 0.1683 \\
\hline 1043 & 4571522.6329 & 647169.1242 & 4571522.7000 & 647169.2980 & 0.0671 & 0.1738 \\
\hline 1046 & 4555861.4332 & 657506.8844 & 4555861.5010 & 657507.0530 & 0.0678 & 0.1686 \\
\hline 1047 & 4547418.1158 & 654015.5479 & 4547418.1860 & 654015.7160 & 0.0702 & 0.1681 \\
\hline 1051 & 4558793.4240 & 666527.9618 & 4558793.4960 & 666528.1350 & 0.0720 & 0.1732 \\
\hline 1057 & 4567889.1230 & 632774.3269 & 4567889.2150 & 632774.4900 & 0.0920 & 0.1631 \\
\hline 1059 & 4569025.5329 & 670922.1698 & 4569025.6000 & 670922.3480 & 0.0671 & 0.1782 \\
\hline 1060 & 4563780.8334 & 673054.6312 & 4563780.8920 & 673054.8050 & 0.0586 & 0.1738 \\
\hline 1069 & 4550626.4246 & 695392.2452 & 4550626.4980 & 695392.4140 & 0.0734 & 0.1688 \\
\hline 1070 & 4549821.1872 & 709655.4251 & 4549821.2610 & 709655.6040 & 0.0738 & 0.1789 \\
\hline 1073 & 4542814.0288 & 678310.6545 & 4542814.1000 & 678310.8280 & 0.0712 & 0.1735 \\
\hline 1076 & 4556505.8328 & 674024.7009 & 4556505.9010 & 674024.8740 & 0.0682 & 0.1731 \\
\hline 1082 & 4554060.6932 & 733417.8868 & 4554060.7750 & 733418.0710 & 0.0818 & 0.1842 \\
\hline 1083 & 4549251.4406 & 729395.9647 & 4549251.5210 & 729396.1440 & 0.0804 & 0.1793 \\
\hline 1088 & 4561844.8930 & 720079.7593 & 4561844.9850 & 720079.9510 & 0.0920 & 0.1917 \\
\hline 1092 & 4538650.6465 & 629486.5908 & 4538650.7320 & 629486.7330 & 0.0855 & 0.1422 \\
\hline 1096 & 4533201.1617 & 694514.8406 & 4533201.2410 & 694515.0260 & 0.0793 & 0.1854 \\
\hline 1100 & 4517398.0544 & 705998.5364 & 4517398.1370 & 705998.7060 & 0.0826 & 0.1696 \\
\hline
\end{tabular}


Table 2. Coordinates of IGS Stations of TNFGN.

\begin{tabular}{lcrc}
\hline \multirow{2}{*}{ Station ID } & \multicolumn{3}{c}{ ITRF96 Coordinates at Epoch 1997.0 } \\
\cline { 2 - 4 } & $\mathrm{X}(\mathrm{m})$ & \multicolumn{1}{c}{$\mathrm{Y}(\mathrm{m})$} & $\mathrm{Z}(\mathrm{m})$ \\
\hline ANKR & 4121948.602 & 2652187.958 & 4069023.671 \\
WTZR & 4075580.697 & 931853.669 & 4801568.044 \\
MATE & 4641949.718 & 1393045.282 & 4133287.333 \\
ONSA & 3370658.674 & 711877.032 & 5349786.866 \\
KIT3 & 1944945.365 & 4556652.206 & 4004325.969 \\
ZWEN & 2886325.555 & 2155998.407 & 5245816.135 \\
NICO & 4359415.854 & 2874116.991 & 3650777.707 \\
BAHR & 3633909.068 & 4425275.486 & 2799861.265 \\
\hline
\end{tabular}

Table 3. Coordinates of IGS Stations of CORS-TR (CORS-TR Report, 2006).

\begin{tabular}{lccc}
\hline Station ID & \multicolumn{3}{c}{ ITRF2000 Coordinates at Epoch 1997.0 } \\
\cline { 2 - 4 } & $\mathrm{X}(\mathrm{m})$ & $\mathrm{Y}(\mathrm{m})$ & $\mathrm{Z}(\mathrm{m})$ \\
\hline ANKR & 4121948.524 & 2652187.904 & 4069023.758 \\
TUBI & 4211317.316 & 2377865.929 & 4144663.268 \\
DRAG & 4432980.620 & 3149432.112 & 3322110.468 \\
NOT1 & 4934546.203 & 1321265.036 & 3806456.124 \\
SOFI & 4319372.078 & 1868687.819 & 4292063.947 \\
BUCU & 4093760.836 & 2007793.835 & 4445129.965 \\
MATE & 4641949.526 & 1393045.455 & 4133287.465 \\
\hline
\end{tabular}

\section{Determination of strain accumulation}

\subsection{Determination of strain in a network with the global test}

In this study, to analyse significant deformation between two epochs and strain parameters in 3-D, a global test was applied to the network. Free network adjustment was introduced for each campaign. For the global test, the differences of 3-D coordinates of two epochs were used. These differences (Fig. 1) were taken as the vector of deformations (Brunner, 1979).

The general equation of the vector of deformations can be written as;

$d=B u$,

where $\mathbf{B}$ is the matrix of coefficients for one common station, $\boldsymbol{u}$ is the vector of unknown parameters (translations $t$, extensions $\varepsilon$, shearing strain $\gamma$ and rotations $\omega$ ).

$\mathbf{B}=\left|\begin{array}{rrrrrrrrrrrr}1 & 0 & 0 & \mathrm{x} & 0 & 0 & \mathrm{y} & \mathrm{z} & 0 & 0 & \mathrm{z} & -\mathrm{y} \\ 0 & 1 & 0 & 0 & \mathrm{y} & 0 & \mathrm{x} & 0 & \mathrm{z} & -\mathrm{z} & 0 & \mathrm{x} \\ 0 & 0 & 1 & 0 & 0 & \mathrm{z} & 0 & \mathrm{x} & \mathrm{y} & \mathrm{y} & -\mathrm{x} & 0\end{array}\right|$,

$\boldsymbol{u}=\left(\mathbf{B}^{T} \mathbf{B}\right)^{-1} \mathbf{B}^{T} d$,

where $d$ is the coordinate differences.
Root mean square error of the a posteriori unit weight is calculated by

$m_{0}= \pm \sqrt{\frac{\boldsymbol{v}^{T} \boldsymbol{v}}{n-u}}= \pm 0.02324$

where $\boldsymbol{v}$ is the coordinate residual vector, $n$ is the number of coordinates included in the global test, $u$ donates to the number of unknowns. Below the parameter vector $\boldsymbol{u}$ is shown with their corresponding precisions.

$$
\boldsymbol{u}=\left|\begin{array}{c}
t_{\mathrm{x}} \\
t_{\mathrm{y}} \\
t_{\mathrm{z}} \\
\varepsilon_{11} \\
\varepsilon_{22} \\
\varepsilon_{33} \\
\frac{1}{2} \gamma_{12} \\
\frac{1}{2} \gamma_{23} \\
\frac{1}{2} \gamma_{13} \\
\omega_{11} \\
\omega_{22} \\
\omega_{33}
\end{array}\right|=\left|\begin{array}{r}
-0.12540 \pm 0.00413 \\
0.13045 \pm 0.00522 \\
0.05817 \pm 0.00351 \\
0.00085 \pm 0.00075 \\
0.00136 \pm 0.00070 \\
-0.00038 \pm 0.00024 \\
0.00095 \pm 0.00073 \\
-0.00012 \pm 0.00040 \\
0.00207 \pm 0.00064 \\
-0.00203 \pm 0.00063 \\
-0.00011 \pm 0.00034 \\
0,00080 \pm 0.00061
\end{array}\right|_{\text {ITRF96 }}
$$

t-test at $95 \%$ confidence interval was applied with $f=135$ (degrees of freedom) and $\alpha=0.05$ (significance level) to the results. Then, t-test critical value became $t_{0.95}=1.658$.

The results revealed that there were significant translations $\left(t_{\mathrm{x}}, t_{\mathrm{y}}, t_{\mathrm{z}}\right)$, strain accumulation $\left(\varepsilon_{22}\right)$ in the network. There was also a significant rotation around $x\left(\omega_{11}\right)$ and a shearing strain $\left(\gamma_{13}\right)$. Values of strain accumulation $\left(\varepsilon_{11}\right)$, rotation around $\mathrm{z}$-axis $\left(\omega_{33}\right)$ and shearing strain $\left(\gamma_{12}\right)$ were close to being statistically significant. These results show that there are deformations in the directions of $\mathrm{x}, \mathrm{y}$ and $\mathrm{z}$ axis.

\subsection{Determination of strain accumulation by finite element model}

As seen in Sect. 4.1, there were significant translations and rotations in the network. Therefore, the selection of an independent way of determining strain accumulation from datum parameters should be done. The ratio of baselines is independent from datum. Consequently, a model of calculating strain parameters with ratio of baselines, which is called finite element model, was used in this study.

Least square adjustment is applied to observations at two epochs separately. Linear extension of a baseline in a network become

$\varepsilon=\frac{S^{\prime}-S}{\Delta t \cdot S}$,

where $S$ is the baseline at epoch $\left(t_{1}\right), S^{\prime}$ is the baseline length at epoch $\left(t_{2}\right), \Delta t$ is the time interval $\left(t_{2}-t_{1}\right)$ between two epochs.

If the time interval between two epochs, $\Delta t$ is known, strain rate $\varepsilon$ can be derived. However, if $\Delta t$ is not taken into account, $\varepsilon$ will become strain accumulation. 
Table 4. Transformation parameters of epoch 2000.45 and 2006.60.

\begin{tabular}{lcc}
\hline & TNFGN & CORS-TR \\
\hline Scale & $1 .+0.001 \mathrm{ppm} \pm 0.0006 \mathrm{ppm}$ & $1 .+0.19 \mathrm{ppm} \pm 0.027 \mathrm{ppm}$ \\
Rotation about X axis & $-0.00046^{\prime \prime} \pm 0.00014^{\prime \prime}$ & $-0.011^{\prime \prime} \pm 0.013^{\prime \prime}$ \\
Rotation about Y axis & $0.00027^{\prime \prime} \pm 0.00021^{\prime \prime}$ & $0.001^{\prime \prime} \pm 0.029^{\prime \prime}$ \\
Rotation about Z axis & $-0.00003^{\prime \prime} \pm 0.00015^{\prime \prime}$ & $-0.004^{\prime \prime} \pm 0.006^{\prime \prime}$ \\
Translation along X axis & $0.015 \pm 0.006 \mathrm{~m}$ & $-0.639 \pm 0.613 \mathrm{~m}$ \\
Translation along Y axis & $0.019 \pm 0.004 \mathrm{~m}$ & $-0.322 \pm 0.255 \mathrm{~m}$ \\
Translation along Z axis & $-0.022 \pm 0.005 \mathrm{~m}$ & $-1.008 \pm 0.725 \mathrm{~m}$ \\
\hline
\end{tabular}

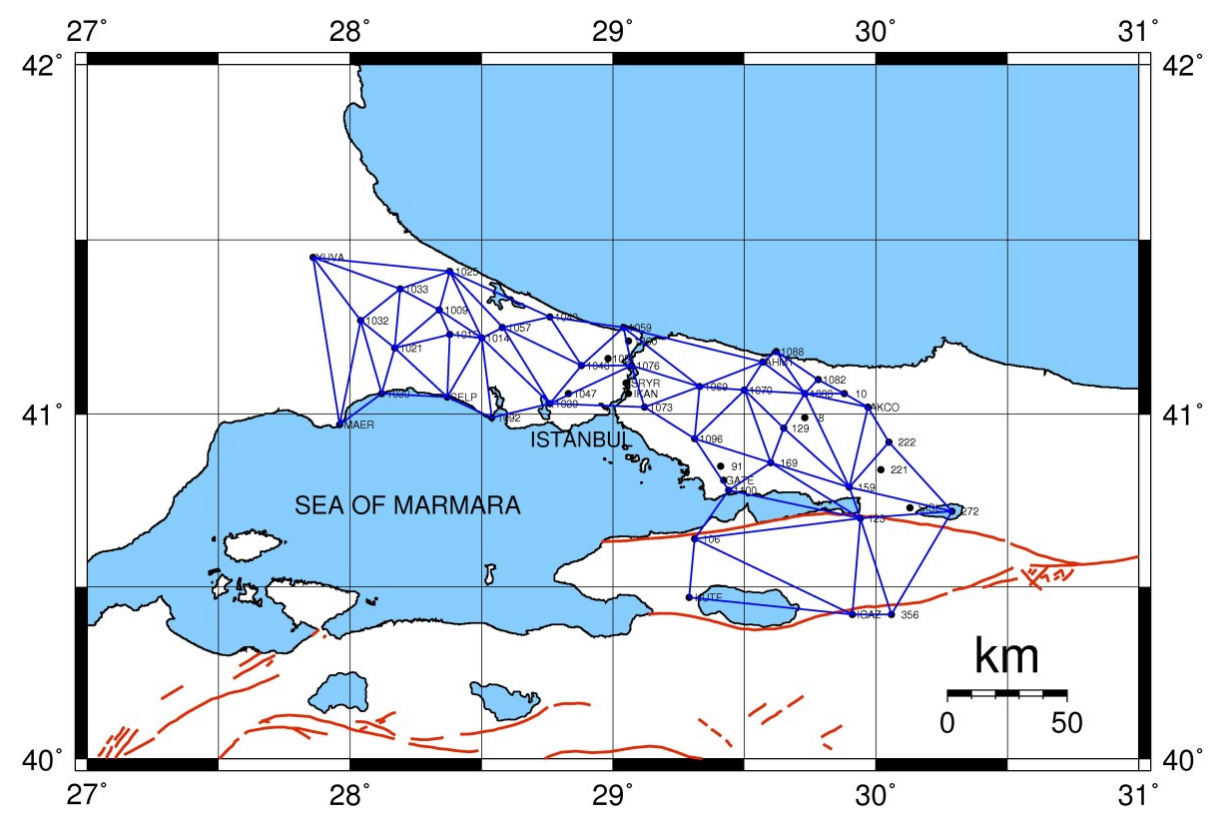

Fig. 2. Triangulation of the network.

Linear extension of the baseline which has $t$ azimuth is,

$\varepsilon=e_{\mathrm{xx}} \cos ^{2} t+e_{\mathrm{xy}} \sin 2 t+e_{\mathrm{yy}} \sin ^{2} t$.

where $e_{\mathrm{xx}}, e_{\mathrm{xy}}$ and $e_{\mathrm{yy}}$ are the strain tensor parameters. In order to calculate parameters of strain tensor, the general equation written above is used. The network has to be constructed of triangles. Then strain tensor has to be calculated for each triangle in the network. Three general equations are created for each baseline of a triangle. In this study, triangles for the network were constructed by using the Delaunay triangulation method. In the case of the intersection of the fault and baseline of a triangle, linear extension of the baseline was the sum of the translation component and strain component. Error strain could be obtained from the results in this situation. Therefore, triangles were simplified and designed not to intersect with the fault (Fig. 2).

Thus, $e_{\mathrm{xx}}, e_{\mathrm{xy}}, e_{\mathrm{yy}}$ for each triangle are found for time interval between 2000.45 and 2006.60 epochs. These parameters of strain tensor are the strain parameters of the point of equilibration of each triangle (Salmon, 1931; Denli, 1998). Subsequently, strain parameters shown below could be calculated from the parameters of strain tensor (Salmon, 1931; Deniz, 1997).

$$
\begin{aligned}
\Delta & =e_{\mathrm{xx}}+e_{\mathrm{yy}}, \\
\gamma_{1} & =e_{\mathrm{xx}}-e_{\mathrm{yy}}, \\
\gamma_{2} & =2 e_{\mathrm{xy}}, \\
\gamma & =\sqrt{\gamma_{1}^{2}+\gamma_{2}^{2}},
\end{aligned}
$$

where $\Delta$ is dilatancy, $\gamma_{1}$ is principal shear strain, $\gamma_{2}$ is engineering shear strain and $\gamma$ is total shear strain.

Principal strain parameters are calculated by the following equations.

$$
\begin{aligned}
& E_{1}=\frac{1}{2}(\Delta+\gamma), \\
& E_{2}=\frac{1}{2}(\Delta-\gamma),
\end{aligned}
$$




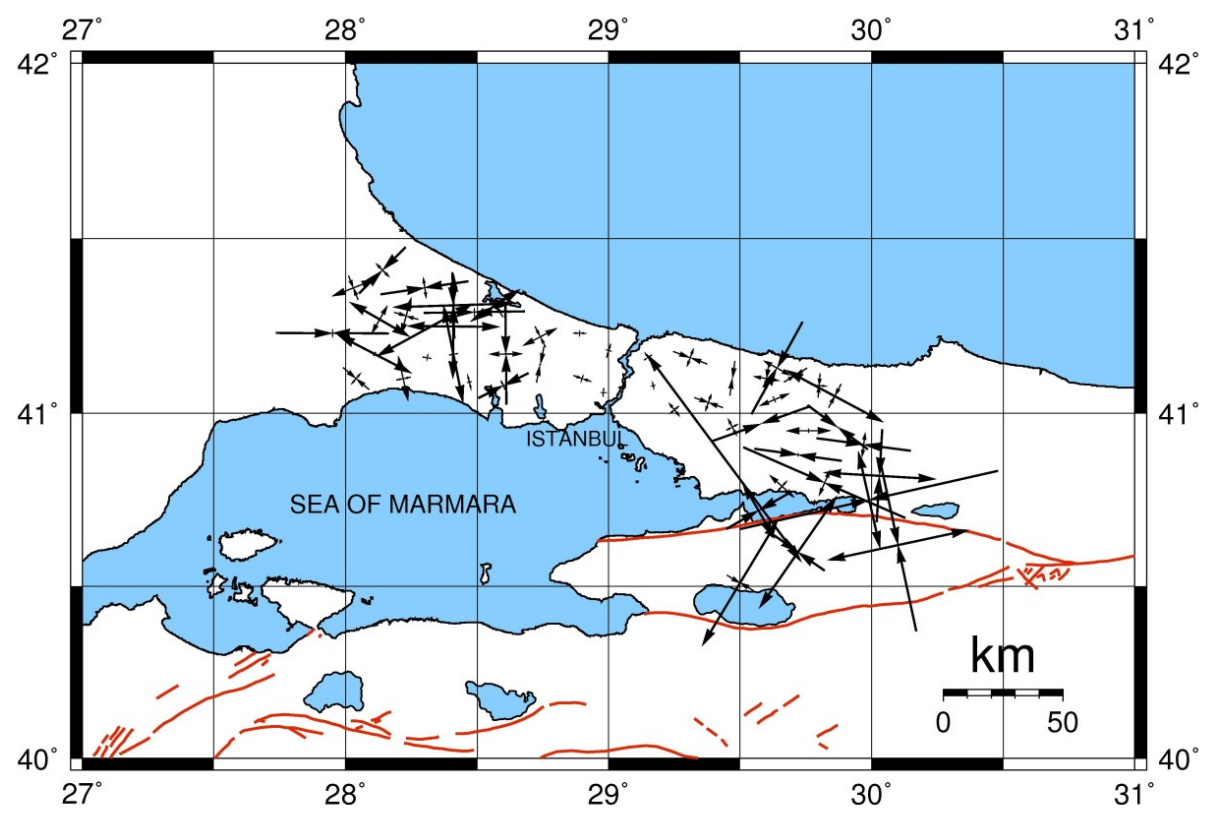

Fig. 3. Principal strain parameters of the network.

$$
\beta=\arctan \left(\frac{e_{\mathrm{xy}}}{E_{1}-e_{\mathrm{xy}}}\right),
$$

where $E_{1}$ is maximum principal strain, $E_{2}$ is minimum principal strain and $\beta$ is direction of maximum principal strain arc.

Equations of maximum shear strain $E_{\text {SHEAR }}$ and maximum normal strain $E_{\mathrm{INTER}}$ are given below.

$$
\begin{aligned}
E_{\text {SHEAR }} & =0.5\left(E_{1}-E_{2}\right), \\
E_{\text {INTER }} & =0.5\left(E_{1}+E_{2}\right) .
\end{aligned}
$$

The process for computing precisions of calculated strain parameters by finite element model is

$C_{\mathrm{xx}}=\left[\begin{array}{cc}m_{\mathrm{x}}^{2} & 0 \\ 0 & m_{\mathrm{y}}^{2}\end{array}\right]=\left[\begin{array}{cc}(1.5 \mathrm{~cm})^{2} & 0 \\ 0 & (1.5 \mathrm{~cm})^{2}\end{array}\right]$

where $C_{\mathrm{xx}}$ denotes the covariance matrix of the adjusted coordinates of TNFGN, IGTN and MERLIS networks.

Mathematical relation between the cofactor matrix is $Q_{\Delta S \Delta S}=4 Q_{\mathrm{xx}}$, it becomes;

$C_{\Delta S \Delta S}=4\left[\begin{array}{cc}m_{\mathrm{x}}^{2} & 0 \\ 0 & m_{\mathrm{y}}^{2}\end{array}\right]=4\left[\begin{array}{cc}(1.5 \mathrm{~cm})^{2} & 0 \\ 0 & (1.5 \mathrm{~cm})^{2}\end{array}\right]$,

and root mean square error of the differences of baselines between two epochs are derived as;

$m_{\Delta S \Delta S}= \pm 4.24 \mathrm{~cm}$.

If the average baseline of test network is taken as $25 \mathrm{~km}$, expected error ratios of strain parameters is

$m_{\varepsilon}=\frac{m_{\Delta S \Delta S}}{S_{\mathrm{av}}}= \pm 1.7 \mathrm{ppm}$.
Principal strain parameters were calculated for the network by a finite element model using a programme coded in FORTRAN language (Deniz, 2007). The differences between the coordinates of 2000.45 and 2006.60 epochs were used for the calculations. Principal strain parameters of each triangle were given in Fig. 3 and Table 5.

Equilibration points, which have close strain parameter values, were gathered into groups in order to simplify the interpretations of the result. Principal strain parameters of each group were shown in Fig. 4.

\section{Results and discussion}

Displacement vectors (Fig. 1) indicates that there were significant displacements within $6.5 \mathrm{~cm}$ and $22.8 \mathrm{~cm}$ between the 2000.45 and 2006.60 epochs.

The results of Helmert transformation (Table 4) revealed that there was a significant translation in the datum of CORSTR.

Choosing the model of calculating strain parameters should be done with respect to the state of the datum of networks. Strain parameters should be calculated from geodetic data which were independent from datum parameters. Finite element model that relied on the deformations of network baselines, which is the most suitable model for the calculation of strain parameters, was used in this study.

Firstly, for this method triangles were formed with Delaunay triangulation method. Triangles which are intersected with the fault were redesigned in order to minimize the errors. Then, strain parameter of equilibration of each triangle was calculated. 
Table 5. Principal strain parameters computed for each triangle in the network.

\begin{tabular}{|c|c|c|c|c|c|c|c|}
\hline \multirow[t]{2}{*}{$\begin{array}{l}\text { Triangle Corner } \\
\text { Points }\end{array}$} & \multicolumn{2}{|c|}{$\begin{array}{c}\text { Coordinates of Point } \\
\text { of Equilibration }\end{array}$} & \multicolumn{2}{|c|}{$\begin{array}{c}\text { Principal Strain } \\
\text { Components }\end{array}$} & \multirow[t]{2}{*}{$\begin{array}{l}\text { Angle of the Principal } \\
\text { Strain } \beta \text { (grad) }\end{array}$} & \multirow[t]{2}{*}{$\begin{array}{c}E_{\text {INTER }} \\
(\mu \mathrm{s})\end{array}$} & \multirow[t]{2}{*}{$\underset{(\mu \mathrm{s})}{E_{\text {SHEAR }}}$} \\
\hline & North (m) & East (m) & $E_{1}(\mu \mathrm{s})$ & $E_{2}(\mu \mathrm{s})$ & & & \\
\hline YUVA,MAER, 1032 & 4564617.001 & 579857.906 & 0.25 & -3.18 & -0.40 & -1.46 & 1.72 \\
\hline MAER,1032,1030 & 4550366.541 & 587324.662 & 0.45 & -0.95 & -44.81 & -0.25 & 0.70 \\
\hline $1032,1030,1021$ & 4558601.663 & 593234.019 & 2.37 & -0.13 & 69.52 & 1.12 & 1.25 \\
\hline YUVA,1032,1033 & 4579204.054 & 586166.72 & 1.33 & -0.73 & -76.22 & 0.30 & 1.03 \\
\hline $1032,1033,1021$ & 4569685.287 & 595027.499 & 1.97 & 0.89 & 66.87 & 1.43 & 0.54 \\
\hline $1033,1021,1009$ & 4571129.006 & 603388.008 & 1.10 & -0.71 & -17.26 & 0.19 & 0.91 \\
\hline YUVA,1033,1025 & 4584746.453 & 595696.597 & 0.57 & -1.84 & 49.63 & -0.63 & 1.21 \\
\hline $1033,1025,1009$ & 4579360.606 & 609043.541 & 0.61 & -2.51 & 9.28 & -0.95 & 1.56 \\
\hline $1025,1009,1014$ & 4574243.446 & 617617.55 & 3.41 & -1.86 & -98.06 & 0.78 & 2.64 \\
\hline 1030,SELP,1021 & 4550833.981 & 602520.229 & 1.32 & -0.43 & 13.99 & 0.45 & 0.87 \\
\hline SELP,1021,1015 & 4556990.662 & 609713.515 & 0.22 & -0.24 & -11.56 & -0.01 & 0.23 \\
\hline $1021,1009,1015$ & 4566202.064 & 608787.815 & 3.10 & -0.02 & -68.16 & 1.54 & 1.56 \\
\hline $1009,1015,1014$ & 4567436.834 & 617761.281 & 2.97 & 2.63 & -0.52 & 2.80 & 0.17 \\
\hline 1015,1014,SELP & 4558225.433 & 618686.981 & 2.83 & -0.25 & 12.67 & 1.29 & 1.54 \\
\hline SELP,1092,1014 & 4549469.275 & 623215.786 & 0.47 & -0.12 & 15.62 & 0.17 & 0.29 \\
\hline $1092,1014,1039$ & 4548874.055 & 634230.639 & 0.34 & -1.57 & 29.92 & -0.62 & 0.96 \\
\hline $1025,1014,1057$ & 4572525.515 & 624555.365 & 0.28 & -2.85 & 0.85 & -1.29 & 1.57 \\
\hline $1014,1057,1039$ & 4558620.214 & 635326.551 & -0.97 & -2.85 & -99.51 & -1.91 & 0.94 \\
\hline $1057,1039,1046$ & 4555791.203 & 646021.251 & -0.05 & -1.03 & 87.41 & -0.54 & 0.49 \\
\hline $1025,1057,1043$ & 4574916.904 & 631804.145 & 1.69 & -0.77 & -63.24 & 0.46 & 1.23 \\
\hline $1057,1043,1046$ & 4565091.063 & 645816.779 & 1.11 & -0.65 & -69.88 & 0.23 & 0.88 \\
\hline $1043,1046,1059$ & 4565469.866 & 658532.726 & 0.19 & -0.37 & -4.09 & -0.09 & 0.28 \\
\hline $1059,1046,1076$ & 4560464.266 & 667484.585 & 0.21 & -0.39 & 81.74 & -0.09 & 0.30 \\
\hline $1046,1076,1039$ & 4551996.773 & 659771.375 & -0.24 & -0.52 & -21.47 & -0.38 & 0.14 \\
\hline $1076,1039,1073$ & 4547647.638 & 666705.965 & 0.20 & -0.24 & 97.69 & -0.02 & 0.22 \\
\hline $1059,1076,1069$ & 4558719.263 & 680113.039 & 0.37 & -0.25 & 37.92 & 0.06 & 0.31 \\
\hline $1076,1069,1073$ & 4549982.095 & 682575.867 & 0.25 & 0.13 & 12.83 & 0.19 & 0.06 \\
\hline $1069,1073,1096$ & 4542213.872 & 689405.913 & 0.52 & -0.33 & 43.61 & 0.09 & 0.42 \\
\hline 1059,1069,AHMT & 4559427.308 & 694107.826 & 0.56 & -1.02 & -22.71 & -0.23 & 0.79 \\
\hline 1069,AHMT,1070 & 4553025.859 & 707018.911 & -0.03 & -0.98 & 91.19 & -0.50 & 0.47 \\
\hline АНМТ,1070,1083 & 4552567.531 & 718353.484 & 0.75 & -0.85 & 89.48 & -0.05 & 0.80 \\
\hline $1069,1096,1070$ & 4544549.591 & 699854.170 & 0.54 & -0.85 & -21.56 & -0.16 & 0.70 \\
\hline $1096,1070,169$ & 4536983.826 & 707813.556 & 0.57 & -0.37 & 30.29 & 0.10 & 0.47 \\
\hline $1070,169,129$ & 4538954.631 & 717474.452 & -0.04 & -2.94 & 21.70 & -1.49 & 1.45 \\
\hline АНMT,1088,1083 & 4556575.433 & 721828.262 & 0.87 & -2.96 & 67.99 & -1.05 & 1.92 \\
\hline $1088,1083,1082$ & 4555052.342 & 727631.204 & 0.10 & -0.75 & 34.52 & -0.32 & 0.43 \\
\hline $1083,1082,10$ & 4551671.552 & 734917.659 & 0.47 & -0.68 & 94.74 & -0.11 & 0.57 \\
\hline 10,AKCO,1083 & 4548625.003 & 740388.899 & 3.14 & -0.76 & 68.77 & 1.19 & 1.95 \\
\hline AKCO,1083,159 & 4538448.998 & 741455.933 & -0.02 & -2.10 & -40.57 & -1.06 & 1.04 \\
\hline $1083,159,129$ & 4536513.175 & 732677.908 & 1.28 & -0.12 & -99.59 & 0.58 & 0.70 \\
\hline $129,159,169$ & 4529405.737 & 729302.721 & 0.12 & -2.48 & -8.62 & -1.18 & 1.30 \\
\hline $159,169,123$ & 4520159.483 & 737570.536 & 0.81 & -4.98 & -26.17 & -2.08 & 2.90 \\
\hline $169,123,1100$ & 4518900.665 & 724523.305 & 0.96 & 0.46 & 53.04 & 0.71 & 0.25 \\
\hline AKCO,222,159 & 4533447.543 & 750518.843 & 0.70 & -2.68 & -8.25 & -0.99 & 1.69 \\
\hline 222,159,SISL & 4522942.709 & 755411.91 & 3.18 & -2.61 & 96.29 & 0.28 & 2.90 \\
\hline 159,SISL, 123 & 4515318.621 & 752650.671 & 2.81 & -7.43 & 14.12 & -2.31 & 5.12 \\
\hline $1096,169,1100$ & 4526176.115 & 706594.593 & 0.85 & 0.29 & 92.14 & 0.57 & 0.28 \\
\hline KUTE,106,IGAZ & 4487928.319 & 712030.332 & 4.14 & -0.87 & -34.53 & 1.63 & 2.50 \\
\hline $1070,1083,129$ & 4546062.068 & 720849.64 & 0.92 & -0.17 & -74.74 & 0.37 & 0.55 \\
\hline $272,356,123$ & 4501183.418 & 762112.396 & 4.09 & -4.97 & -86.56 & -0.44 & 4.53 \\
\hline 123,IGAZ,106 & 4497626.561 & 730183.782 & 3.86 & -1.83 & -38.58 & 1.02 & 2.85 \\
\hline $1100,123,106$ & 4510545.178 & 716666.553 & 1.84 & -2.10 & 33.36 & -0.79 & 2.62 \\
\hline
\end{tabular}




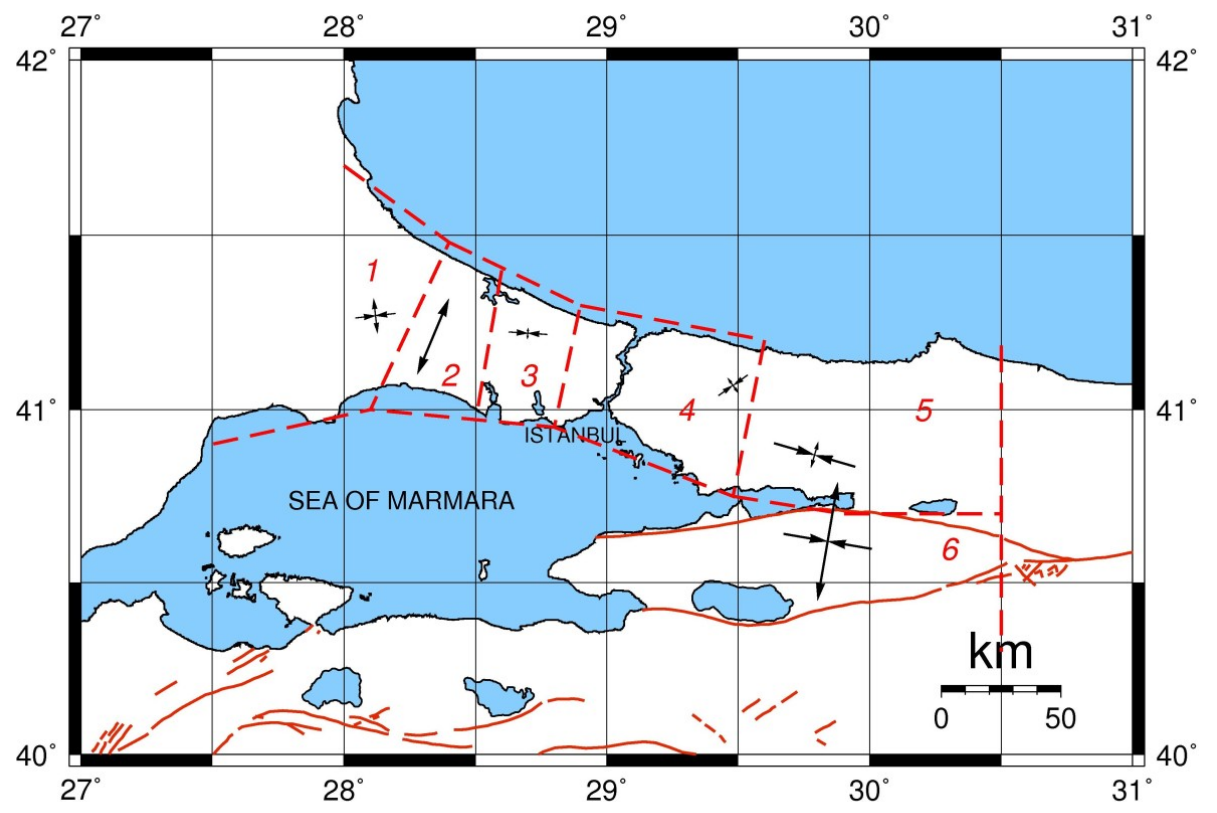

Fig. 4. Principal strain parameters of each group.

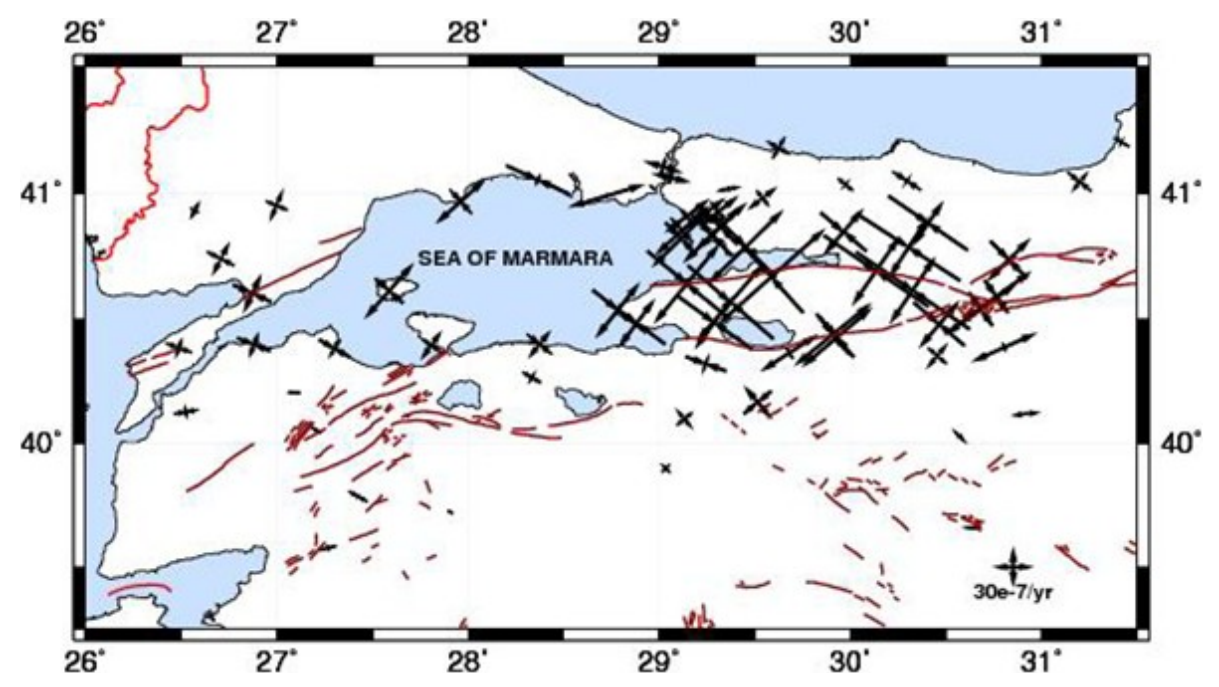

Fig. 5. Principal strain rates from the study of Ozener et al. (2009).

Majority of strain parameters of the network obtained from the three dimensional differences were significant. The results of the global test indicated that there was a significant deformation in the network.

Baseline ratios, which were computed for baselines of triangles, were compared with $m \varepsilon= \pm 1.7 \mathrm{~cm}$ which was calculated in Sect. 4.2. The majority of ratios were larger than $2 \mathrm{ppm}$. Therefore, this indicates that calculated strain parameters were significant.

Strain parameters in Table 5 shows that maximum values of strain accumulation were around Marmara Ereglisi and Izmit, while minimum values were around Istanbul.
Although the covered regions by this study and Ozener et al. (2009) do not fully match, they have four stations (AKCO, IGAZ, KUTE and SELP) in common. As well as the directions and signs (compression or extension) of strain parameters of this study are consistent with the results of the study of Ozener et al. (Fig. 5), the scalar values of strain parameters are computed as smaller. This result has been expected since deformation pattern naturally changes over time and besides GPS data span and locations of station points differ from each other in both studies. 
Acknowledgements. The authors gratefully acknowledge the cooperation and valuable comments of Rasim Deniz and Cihangir Ozsamli. Thanks are also due to our colleagues at Istanbul Kultur University, for providing us with the GPS data. Finally, the authors would like to thank the reviewers for their valuable comments that helped to improve the paper.

Edited by: M. E. Contadakis

Reviewed by: K. Teke and another anonymous referee

\section{References}

Altamimi, Z., Collilieux, X., Legrand, J., Garayt, B., and Boucher, C.: ITRF2005, A new release of the International Terrestrial Reference Frame based on time series of station positions and Earth orientation parameters, J. Geophys. Res., 112(B9), B09401, doi:10.1029/2007JB004949, 2007.

Brunner, F. K.: On the Analysis of Geodetic Networks for the Determination of the Incremental Strain Tensor, Survey Review XXV, University of New South Wales, 1979.

Deniz, I.: Determination of Velocity Field and Strain Accumulation of Densification Network in Marmara Region, M.S. thesis, Bogazici University, Istanbul, Turkey, 2007.
Deniz, R.: Jeodezik Verilerden Strain Analizi, Jeodezi Anabilim Dali Seminerleri, Istanbul Technical University, Istanbul, Turkey, 1997 (in Turkish).

Denli, H.: GPS ile Marmara Bolgesindeki Yerkabugu hareketlerinin belirlenmesi, Ph.D. thesis, Istanbul Technical University, Istanbul, Turkey, 1998 (in Turkish).

General Directorate of Land Registry and Cadastre: Marmara Earthquake Region Land Information System Report, 2006.

General Command of Mapping (GCM): Turkish National Fundamental GPS Network Report, available at: http://www.hgk.mil. tr/haritalar_projeler/jeodezi/tutga/default.htm (last access: 17 February 2007), 2001.

Istanbul Kultur University: CORS-TR Benchmark Test Report, Istanbul, Turkey, 2006.

Istanbul Technical University (ITU): Istanbul GPS Triangulation Network Report, Istanbul, Turkey, 1999.

Ozener, H., Dogru, A., and Unlutepe, A.: An Approach for Rapid Assessment of Seismic Hazards in Turkey by Continuous GPS Data, Sensors, 9, 602-615, doi:10.3390/s90100602, 2009.

Salmon, E. H.: Material and Structure, in: The Elasticity and Strength of Material, Vol. 1, Longman, London, United Kingdom, 1931. 